\title{
Spatial scale and the diversity of macroinvertebrates in a Neotropical catchment
}

\author{
RAPHAEL LIGEIRO*, ADRIANO S. MELO ${ }^{+}$AND MARCOS CALLISTO* \\ *Departamento de Biologia Geral, Instituto de Ciências Biológicas, Universidade Federal de Minas Gerais, Belo Horizonte, MG, \\ Brazil \\ ${ }^{\dagger}$ Departamento de Ecologia, Instituto de Biociências, Universidade Federal do Rio Grande do Sul, Porto Alegre, RS, Brazil
}

\section{SUMMARY}

1. Lotic ecosystems can be studied on several spatial scales, and usually show high heterogeneity at all of them in terms of biological and environmental characteristics. Understanding and predicting the taxonomic composition of biological communities is challenging and compounded by the problem of scale. Additive diversity partitioning is a tool that can show the diversity that occurs at different scales.

2. We evaluated the spatial distribution of benthic macroinvertebrates in a tropical headwater catchment (S.E. Brazil) during the dry season and compared alpha and beta diversities at the scales of stream segments, reaches, riffles and microhabitats (substratum types: gravels, stones and leaf litter). We used family richness as our estimate of diversity. Sampling was hierarchical, and included three stream segments, two stream reaches per segment, three riffles per reach, three microhabitats per riffle and three Surber sample units per microhabitat.

3. Classification analysis of the 53 families found revealed groups formed in terms of stream segment and microhabitat, but not in terms of stream reaches and riffles. Separate partition analyses for each microhabitat showed that litter supported lower alpha diversity $(28 \%)$ than did stones $(36 \%)$ or gravel $(42 \%)$. In all cases, alpha diversity at the microhabitat scale was lower than expected under a null model that assumed no aggregation of the fauna.

4. Beta diversity among patches of the microhabitats in riffles depended on substratum type. It was lower than expected in litter, similar in stone and higher in gravel. Beta diversities among riffles and among reaches were as expected under the null model. On the other hand, beta diversity observed was higher than expected at the scale of stream segments for all microhabitat types.

5. We conclude that efficient diversity inventories should concentrate sampling in different microhabitats and stream sites. In the present study, sampling restricted to stream segments and substratum types (i.e. excluding riffles and stream reaches) would produce around $75 \%$ of all observed families using $17 \%$ of the sampling effort employed. This finding indicates that intensive sampling (many riffles and reaches) in few stream segments does not result in efficient assessment of diversity in a region.

Keywords: beta diversity, Cerrado, diversity partitioning, hierarchy, taxa richness

Correspondence: Marcos Callisto, Departamento de Biologia Geral, Instituto de Ciências Biológicas, Universidade Federal de Minas Gerais, C.P. 486, Belo Horizonte, MG, CEP 30161-970, Brazil. E-mail: callistom@ufmg.br

Present address: Adriano S. Melo, Departamento de Ecologia, ICB-I, Universidade Federal de Goiás, Caixa Postal 131, Goiânia, GO, CEP 74001-970, Brazil. 


\section{Introduction}

The concept of spatial scale, in the context of ecological hierarchies, has received increasing attention in the study of patterns at the population, community and ecosystem levels in terrestrial and aquatic systems (Wu \& Loucks, 1995; Li et al., 2001; Parsons, Thoms \& Norris, 2003; Robson \& Clay, 2005; Stendera \& Johnson, 2005; Erös, 2007; Bonada et al., 2008). Many recent studies have considered rivers as landscapes, composed of a variety of patches nested in a chain of hierarchical scales (Malmqvist, 2002). This has led many authors to use the term 'riverine landscapes' (Tockner et al., 2002; Ward et al., 2002), emphasising hierarchies of scale and that the patterns and processes that emerge are dependent on the scale of observation (Giller, Hildrew \& Raffaelli, 1994; Wu \& Loucks, 1995; Tylianakis et al., 2006; Mykrä, Heino \& Muotka, 2007; Bonada et al., 2008).

Studies on lotic systems have focused on many spatial scales, from centimetres (e.g. flow heterogeneity around the substratum; Bouckaert \& Davis, 1998) to kilometres (e.g. land-use effects; Townsend et al., 1997). A number of scales can be recognised in the natural spatial hierarchy of rivers. Among these, many authors have considered microhabitats, habitats, stream reaches, stream segments and catchments (Frissell et al., 1986; Hildrew \& Giller, 1994; Li et al., 2001; Allan \& Castillo, 2007). All these scales encompass heterogeneity in terms of biotic and abiotic conditions (Downes, Lake \& Schreiber, 1993; Heino, Louhi \& Muotka, 2004). For instance, early studies recognised the patchy nature of energy resources and the fauna in streams (Egglishaw, 1964; Townsend, 1989). Such heterogeneity is a result of multiple factors, including biotic interactions (McAuliffe, 1984; Hildrew \& Giller, 1994), disturbance (Matthaei, Arbuckle \& Townsend, 2000; Melo et al., 2003), habitat heterogeneity (Robson \& Chester, 1999; Costa \& Melo, 2008) and population stochasticity (Bunn \& Hughes, 1997). At larger spatial scales, for example drainage systems and ecoregions, heterogeneity in stream assemblages may result not only from environmental constraints but also from geographical distance (Mykrä et al., 2007).

Understanding and predicting the distribution of organisms in space is a main goal of ecology (Poff, 1997; Finn \& Poff, 2005). Recently, additive diversity partitioning has been favoured as a methodological approach to understand the relative importance of community heterogeneity among several spatial scales (Wagner, Wildi \& Ewald, 2000; Crist et al., 2003; Gering, Crist \& Veech, 2003; Stendera \& Johnson, 2005; Tylianakis et al., 2006; Ribeiro et al., 2008). Despite this increasing use of additive diversity partitioning in terrestrial ecosystems, we are aware of only a few recent studies employing it in temperate streams (Stendera \& Johnson, 2005; Erös, 2007) and none in tropical streams. This paucity of papers reflects the preponderance of research on alpha diversity and its scarcity on beta diversity (Clarke et al., 2008).

In the additive approach, gamma (or regional) diversity is obtained by summing the alpha (local) and beta (turnover) diversities (Crist et al., 2003; Gering et al., 2003). Alpha diversity is defined as the mean number of taxa (or the values of diversity indices) observed in samples taken at a particular spatial scale. Beta diversity is the difference between the alpha diversity at two levels of a hierarchy. Over a hierarchy of scales, it is possible to partition total diversity into alpha and beta diversity at the finest scale and the beta diversity associated with successively greater scales (i.e. the incremental gain of diversity as sampling incorporates higher levels in the hierarchy). Contrasting the magnitude of observed beta diversity at each scale against values generated by a null model allows the recognition of the main sources of community variation in the spatial hierarchy (Crist et al., 2003).

Streams and rivers are among the most threatened ecosystems of the world (Dudgeon et al., 2006), particularly those in the tropics (Boyero \& Bailey, 2001). Estimates of the present biodiversity loss in these ecosystems are alarming (Allan \& Castillo, 2007). Knowledge of the biodiversity in a region is the first step in preserving and restoring ecosystems (Heino et al., 2005). However, basic knowledge of biodiversity is lacking for most tropical areas. For instance, many insect genera and even new family records for large biotic regions have appeared recently in the taxonomical literature (Holzenthal, 1997; Huamantinco \& Nessimian, 2003). For most of the Neotropical region, it is not possible to predict even rough values of species (or genera) richness based on environmental predictors, as is usually done in biological assessment (Norris, 1995). The urgent need for biological inventories in tropical areas is usually challenged by the lack of human and economic resources, making it urgent to develop cost-effective protocols to assess 
biological diversity. One potential strategy is to restrict assessments to spatial scales associated with the widest variations in taxa composition (Boyero \& Bailey, 2001; Heino et al., 2005; Robson, Hogan \& Forrester, 2005; Chandy, Gibson \& Robertson, 2006; Ciesielka \& Bailey, 2007).

Here, we assessed the taxonomic composition and distribution of diversity of stream invertebrates associated with three types of substratum (litter, gravel and stones) over four spatial scales [microhabitats (Surber unit), riffles, stream reaches and stream segments], following the spatial classification of Frissell et al. (1986). Specifically, we aimed to: (i) assess the similarity among samples from different substratum types and scales; (ii) identify the spatial scales associated with the highest beta diversity and (iii) contrast the relative magnitude of the diversity components among the three substratum types. We hypothesise that the total diversity is not homogenously distributed among scales, but concentrated in particular levels of the hierarchy. If this is so, sampling should be concentrated at the scales of larger variation, resulting in the reduction of expenses employed in studies aiming the detection of impacts or monitoring of effectiveness of restoration practices.

\section{Methods}

\section{Study area}

We studied three headwater streams in the Mascates catchment, Parque Nacional da Serra do Cipó, Brazil

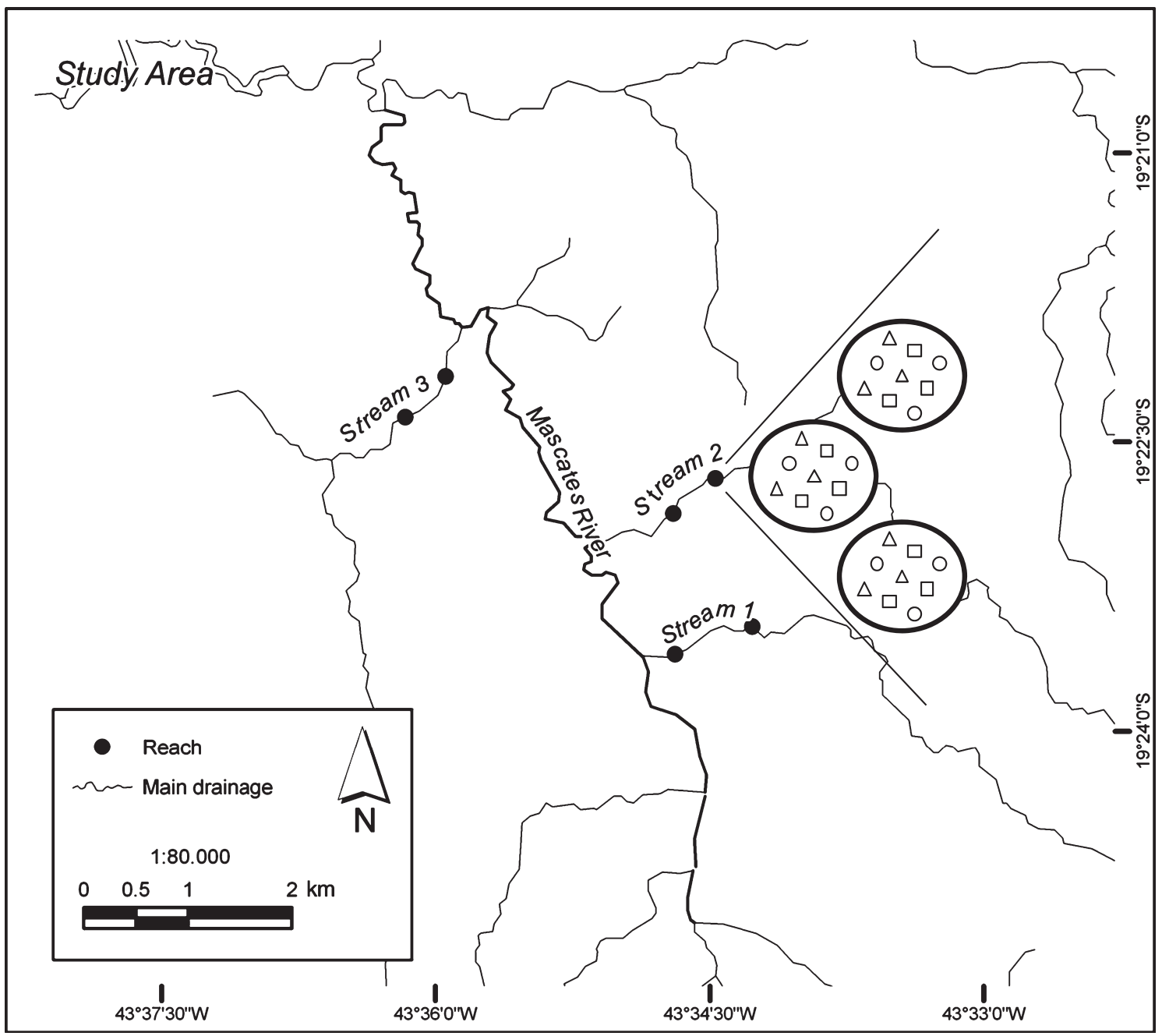

Fig. 1 The Mascates catchment, Parque Nacional da Serra do Cipó, in Minas Gerais, Brazil. The three headwater streams and the approximate positions of the two reaches sampled in each are shown. Within each stream reach, three Surber sampling units were obtained for three types of substratum (litter, gravel and stones; here visualised as different symbols) in each of three riffles. 
$\left(19^{\circ} 20^{\prime} \mathrm{S} ; 43^{\circ} 44^{\prime} \mathrm{W}\right)$ (Fig. 1). The vegetation is Cerrado (savanna), and one of the 25 'biodiversity hotspots' in the world (Myers et al., 2000). The climate is highaltitude tropical (Cwb), with well-marked dry (AprilSeptember) and wet seasons (October-March). Annual mean air temperature ranges from 17 to $18.5^{\circ} \mathrm{C}$ and annual rainfall between 1450 and $1800 \mathrm{~mm}$.

The streams drain relatively pristine catchments within the nature reserve. They are second- and thirdorder and have clear, well-oxygenated waters and are similar in width and depth, with alternating riffles and pools (Table 1). The streambeds are composed mostly of bedrock, stones and leaf-litter banks; gravel is sparse.

\section{Fieldwork and macroinvertebrate identifications}

Field sampling in the three stream sites was done in July 2006, during the dry season. In this period, discharge is constant, habitats are most distinct and densities of invertebrates high (Bispo et al., 2001; Callisto, Moreno \& Barbosa, 2001). Sampling was hierarchical and included microhabitats, riffles, stream reaches and stream segments (Frissell et al., 1986; Allan \& Castillo, 2007) (Fig. 2). The finest spatial scale, hereafter termed microhabitat, consisted of Surber sample units $(30 \times 30 \mathrm{~cm}, 250 \mu \mathrm{m}$ mesh) from different types of substratum. Three Surber sample units were obtained from each of three types of substratum (litter, gravel and stones) per riffle, totalling nine sampling units in each riffle. Surber samples

Table 1 Physicochemical characteristics of the three headwater streams studied (spot measurements during invertebrate sampling)

\begin{tabular}{lccc}
\hline & Stream 1 & Stream 2 & Stream 3 \\
\hline Temperature $\left({ }^{\circ} \mathrm{C}\right)$ & 16.0 & 14.0 & 18.5 \\
Conductivity $\left(\mu \mathrm{S} \mathrm{cm}{ }^{-1}\right)$ & 3.82 & 6.55 & 47.7 \\
$\mathrm{pH}$ & 6.59 & 6.7 & 6.94 \\
Total dissolved solids $(\mathrm{ppm})$ & 5.57 & 9.74 & 67.4 \\
Resistivity $\left(\mathrm{K} \Omega \mathrm{cm}^{-1}\right)$ & 268.0 & 153.9 & 22.0 \\
Turbidity $(\mathrm{NTU})$ & 1.51 & 0.66 & 1.87 \\
Total nitrogen $\left(\mathrm{mg} \mathrm{L}^{-1}\right)$ & 0.6 & $<0.5$ & 2.4 \\
Total phosphorus $\left(\mathrm{mg} \mathrm{L}^{-1}\right)$ & 0.033 & 0.061 & $<0.010$ \\
Dissolved oxygen $\left(\mathrm{mg} \mathrm{L}^{-1}\right)$ & 9.2 & 9.7 & 8.6 \\
Width $(\mathrm{m})$ & 3.05 & 4.5 & 4.5 \\
Depth $(\mathrm{m})$ & 0.26 & 0.18 & 0.29 \\
Current velocity $\left(\mathrm{m} \mathrm{s}^{-1}\right)$ & 0.29 & 0.36 & 0.27 \\
Discharge $\left(\mathrm{m}^{3} \mathrm{~s}^{-1}\right)$ & 0.21 & 0.24 & 0.28 \\
Canopy cover $(\%)$ & 58.3 & 66.67 & 66.67 \\
\hline
\end{tabular}

(c) 2009 Blackwell Publishing Ltd, Freshwater Biology, 55, 424-435

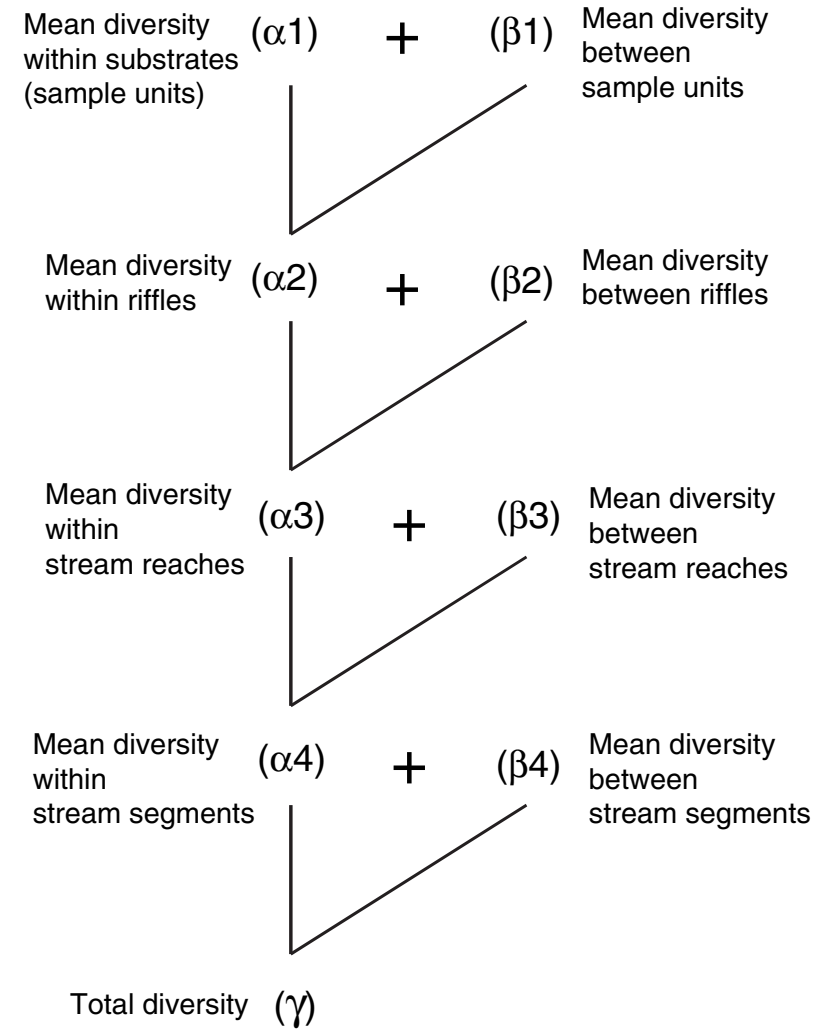

Fig. 2 Additive partitioning of total species richness in alpha and beta components over four spatial scales. Adapted from Stendera \& Johnson (2005).

were located in homogenous areas of each substratum and as far as possible from each other. Microhabitats and substrata were nested within three riffles (habitat), which in turn were nested within two stream reaches and finally in three stream segments (the three headwater streams sampled). Riffles were at least $10 \mathrm{~m}$ long and $50 \mathrm{~m}$ distant from each other within each stream reach. Stream reaches were around $300 \mathrm{~m}$ long and about $800 \mathrm{~m}$ distant from each other (Fig. 1). A total of 162 Surber sample units were obtained (three sampling units $\times$ three substrata $\times$ three riffles $\times$ two stream reaches $\times$ three stream segments $=162$ ). Sample units were preserved using $10 \%$ formalin and sorted in the laboratory.

The material collected was initially sieved through a $250 \mu \mathrm{m}$ mesh. Organisms were sorted and assigned to families. Family level was used since previous studies, including one from the same region (Melo, 2005), have shown that ecological patterns detected using species or morphospecies are also revealed using data for genus or family (Marchant, 1990; Downes, Hindell \& Bond, 2000; Boyero \& Bailey, 2001). 


\section{Statistical analyses}

We first assessed relationships among samples, using a hierarchical clustering method based on the unweighted pairgroup method using arithmetic averages (UPGMA) linkage and the Bray-Curtis distance calculated on $\log (x+1)$ abundance data. For this analysis, the three sampling units (Surbers) for each substratum were pooled, resulting in 54 samples.

We employed additive partitioning to decompose the total variation in taxonomic composition into alpha and beta components. In order to assess whether the relative magnitude of diversity components differed among substratum types, we analysed the data separately for each substratum. Alpha diversity $(\alpha 1)$ is defined as the average number of taxa per sample unit. Beta diversity consists of dissimilarities among samples in terms of taxonomic composition. In this hierarchical study, one value of beta diversity is associated with each spatial level. Accordingly, the first beta component is associated with variation in taxonomic composition among Surber sample units (microhabitats) and is defined as $\beta_{1}$ hereafter. This first beta component can be interpreted as the difference in mean taxon richness between microhabitats (sample units) and habitats (riffles). Similarly, $\beta_{2}$ is the difference in mean taxon richness between habitats and stream reaches, $\beta_{3}$ the difference between stream reaches and stream segments and $\beta_{4}$ the difference between stream segments and the total richness $(\gamma)$ in the study (Fig. 2). Generalising, $\beta_{\mathrm{L}}=\alpha_{\mathrm{L}+1}-\alpha_{\mathrm{L}}$, where $\alpha_{\mathrm{L}+1}$, the mean taxon richness on the upper scale and $\alpha_{\mathrm{L}}$, the mean taxon richness on the lower scale (Gering et al., 2003). In this study, the total taxon richness was partitioned into $\gamma=\alpha_{1}+\beta_{1}+\beta_{2}+\beta_{3}+\beta_{4}$.

In a second partition analysis, we included substratum type as an additional level in the hierarchy, to contrast its importance relative to the four spatial components (see above). In addition to the four spatial beta components described above, this analysis included the component $\beta_{1 \mathrm{~s}}$, the difference in mean taxon richness between substratum types and riffles.

Beta diversity at a given level depends upon the number and size of samples in that level and the one above it (Økland, Eilertsen \& Økland, 1990; Schmera \& Erös, 2008). For instance, beta diversity can be relatively high if many samples are available in the upper level. This results from the pervasive positive dependence of taxa richness on sampling effort.
Comparison of absolute beta diversity values can thus be misleading. An adequate assessment of the relative importance of each beta value can be made using null models. Crist et al. (2003) described two null models for additive partitioning of diversity. The type I model consists of randomisation in the allocation of individuals among all sample units collected in the study. This procedure randomises individuals and taxa simultaneously for all levels in the hierarchy (Gering et al., 2003). In the type II model, samples in level L-1 are randomised within level L, preserving the individuals and taxa present in each sampling unit. We opted to use the type I model, since the random placement of individuals is the null hypothesis of interest (Crist et al., 2003). Note that the randomisation of individuals removes aggregation within sample units, thus allowing us to assess its effect in the hierarchy of scales. We randomised the data according to the null model 10000 times, to generate a distribution of expected values. The observed diversity component value at a given spatial level was then contrasted to the respective random distribution, to determine if it was higher or lower than expected in the absence of aggregation (i.e. the null model). Specifically, we recorded the proportion (hereafter prop-value) of cases in which the null model produced values higher than the observed beta diversity. A low prop-value (e.g. propexp > obs $<0.05$ ) indicates that the observed diversity is significantly higher than that expected under the null model. Similarly, a high prop-value (e.g. prop $\exp _{>}$obs $>0.95$ ) indicates that the observed diversity is significantly lower than that expected under the null model. The analyses were done using the software Partition version 2.0 (Veech \& Crist, 2007).

\section{Results}

A total of 64793 individuals and 53 families were obtained. Most taxa were rare; $81 \%$ occurred with abundances less than $1 \%$. More individuals were obtained in streams 1 and 3 (23 655 and 24923 individuals, respectively) than in stream 2 (16 215 individuals). In terms of substrata, higher densities were observed in the gravel and decomposing leaves (26 146 and 23788 individuals, respectively) than on stones (14 859). Families were distributed widely among streams and substrata. For instance, stream 1 had the highest richness with 47 families ( $89 \%$ of the 
total). Similarly, decomposing leaves contained the highest number of families (51, representing $96 \%$ of the total observed in the study). Insects were dominant in terms of abundance $(96 \%)$ and number of families (90\%). The insect orders Diptera, Trichoptera and Coleoptera contributed with 10 families each. The orders Heteroptera, Ephemeroptera and Odonata contributed with three to seven families each. There was only a single family each of Plecoptera, Megaloptera, Lepidoptera and Turbellaria.

The UPGMA analysis produced groups mostly according to substratum type and stream segment (Fig. 3). Samples from gravel and stones tended to be grouped together and at lower values of dissimilarity than those from litter. Four groups were formed at a dissimilarity of 0.36: (i) the gravel/stones samples from the three streams plus the litter samples from stream 3; (ii) the litter samples from stream 1; (iii) the litter samples from stream 2 and (iv) a single sample (2-1-1-Li; Fig. 3) containing few individuals and taxa. These groupings show that in two streams the litter samples were more dissimilar than samples from other microhabitats. However, this was not true in stream 3 , where all three substratum types were more similar than in the other streams. The effects of riffles and stream reaches were relatively slight.

The mean number of families per Surber sample unit $\left(\alpha_{1}\right)$ was similar among substrata (14.2, 15.3 and 16.2 , respectively for litter, stones and gravel). For all substrata, observed taxa richness in microhabitats was lower than expected under the null model ( prop $_{\exp }>$ obs $>0.999$ ). However, $\alpha_{1}$ for litter represented a smaller fraction $(28 \%)$ of the total diversity than for the rocky substrata $(36 \%$ and $42 \%$ respectively for stone and gravel) (Fig. 4). This indicates a higher aggregation among families occurring on the litter substratum than in those in the gravel/stones substrata, reflecting similar spatial patchy distribution of confamilial individuals.

The relative magnitude of the $\beta_{3}$ component (among stream reaches) was usually low and identical in all three substrata $(11 \%)$. The magnitudes of the $\beta_{1}$ (microhabitat) and $\beta_{2}$ (riffles) were intermediate and similar to each other in all substrata (range: 13-19\%). In contrast, the $\beta_{4}$ component (stream segment) was dependent on substratum type and was high in litter $(29 \%)$, intermediate in stone $(21 \%)$ and low in gravel (15\%). The high values of the $\beta_{4}$ component for litter and stone are concordant with the grouping of

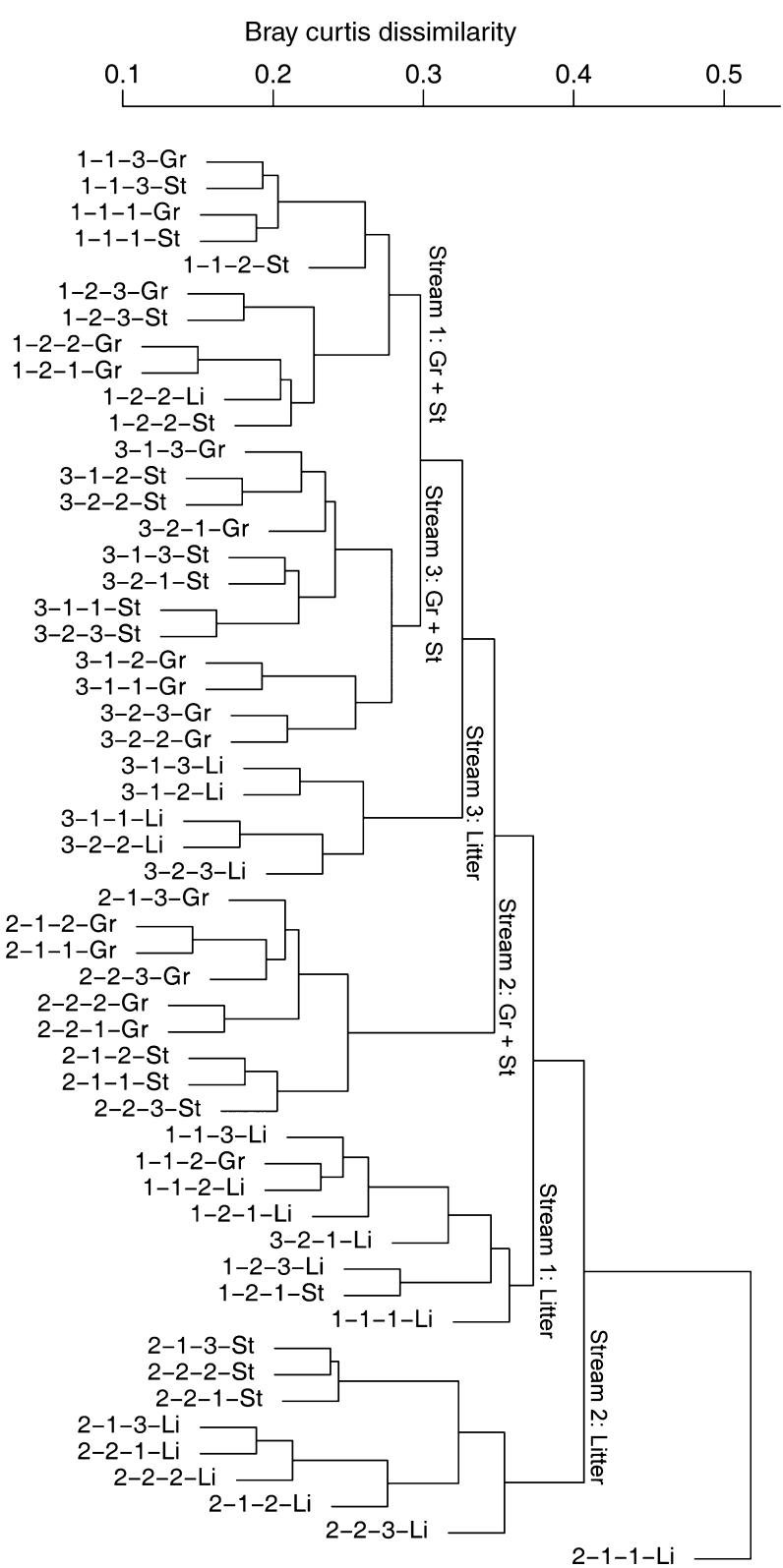

Fig. 3 Classification analysis (UPGMA using Bray-Curtis dissimilarity) of stream macroinvertebrate samples obtained in three stream segments, two stream reaches per segment, three riffles per reach and three microhabitats in each riffle. The first number of the sample label indicates the stream segment. The second number indicates the reach and the third number indicates the riffle. The two letters indicate the microhabitat (substratum type: Gr, gravel; St, stone; Li, litter).

samples according to stream segment in the classification analysis.

The magnitude of the $\beta_{1}$ component (microhabitats) in relation to expectations under the null model was dependent on the type of substratum. Observed values were lower than expected for 

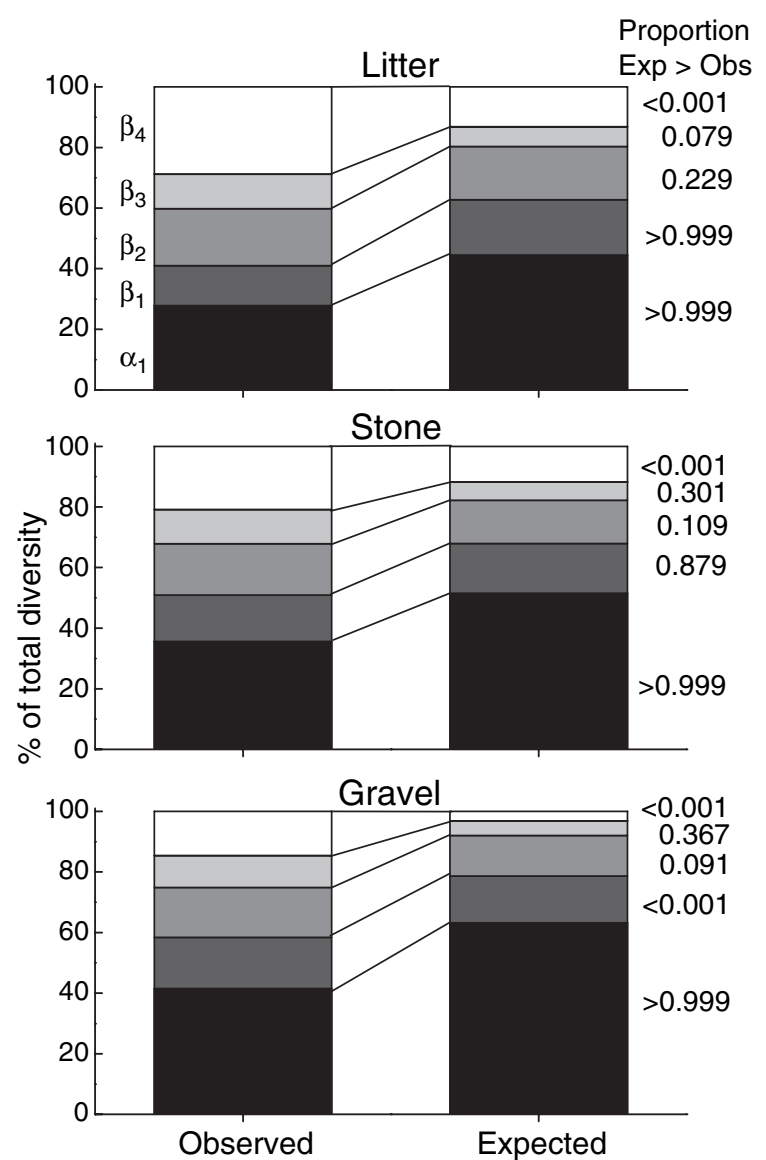

Fig. 4 Observed and expected diversity, partitioned into alpha and four beta components, expressed as per cent of total family richness. Numbers indicate the proportion of randomised samples containing more species than the observed sample for each partition. $\alpha_{1}$, mean species richness per Surber sampling unit; $\beta_{1}$, beta diversity among Surber sampling units in riffles; $\beta_{2}$, beta diversity among riffles; $\beta_{3}$, beta diversity among stream reaches; $\beta_{4}$, beta diversity among stream segments.

litter (propexp $>$ obs $>0.999$ ), similar for stones (propexp $>$ obs $=0.879)$ and higher for gravel ( prop $_{\exp }>$ obs $<0.001$ ). The $\beta_{2}$ (riffle) and $\beta_{3}$ components (reach) of all substrata were roughly similar to those expected $\left(0.367>\right.$ prop $_{\text {exp }}>$ obs $\left.>0.030\right)$. However, $\beta_{4}$ (stream segment) for all substrata was higher than expected under the null model ( prop $_{\text {exp }}>$ obs $<0.001$ ).

The partition analysis, including data from all three substrata, was similar to the analyses of each substratum (Fig. 5). Observed $\alpha_{1}$ and $\beta_{1}$ components were lower and the $\beta_{4}$ higher than expected under the null model. Within riffles, the variation among Surber samples of a substratum (13\%) was roughly similar to the variation among substratum types (15\%) (Fig. 5).

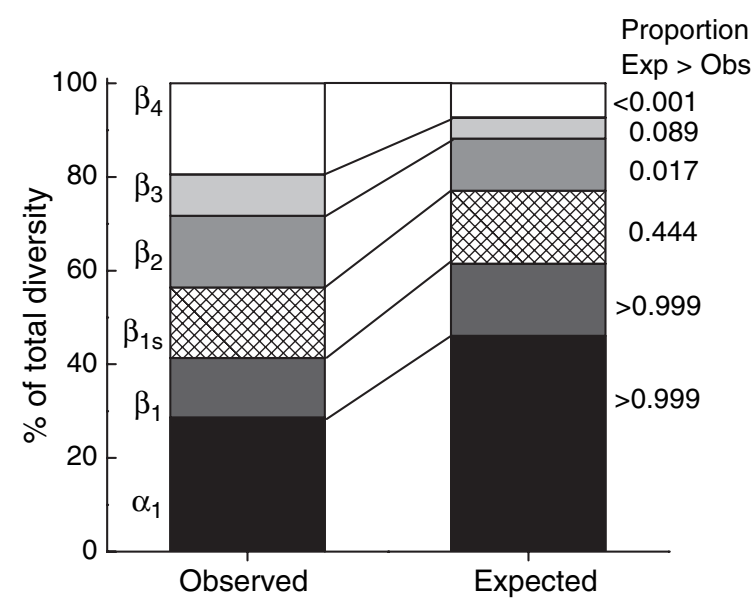

Fig. 5 Observed and expected diversity partitioned in alpha and five beta components, expressed as percent of total species richness. Numbers indicate the proportion of randomised samples containing more species than the observed sample for each partition. $\alpha_{1}$, mean species richness per Surber sampling unit; $\beta_{1}$, beta diversity among Surber sampling units in riffles; $\beta_{1 \mathrm{~S}}$, beta diversity among the three substratum types (litter, stones and gravel); $\beta_{2}$, beta diversity among riffles; $\beta_{3}$, beta diversity among stream reaches; $\beta_{4}$, beta diversity among stream segments.

\section{Discussion}

Except for substratum type, our sampling was random within each spatial scale. Accordingly, differences in family composition among sample units in the same substratum are due mostly to true spatially or environmentally structured variation. The main result of the classification analysis was the grouping of samples (pooling of three sampling units of the same substratum in the same riffle) according to stream segments and substratum type. Stream reaches were relatively unimportant in the determination of similarity among samples. The diversity partitioning analyses provided additional support for the importance of stream segments $\left(\beta_{4}\right)$ and the unimportance of stream reaches. Additionally, the analyses revealed the unimportance of riffles and the dependence of the magnitude of the beta diversity among microhabitats $\left(\beta_{1}\right)$ on substratum type (not evaluated in the classification analysis). In terms of substratum type, the taxon composition on litter differed from that on rocky (gravel + stone) substrata, showing proportionally lower diversity within the finest scale $\left(\alpha_{1}\right)$ and complementary higher diversity at the highest scale $\left(\beta_{4}\right)$.

The importance of substratum type for the composition of stream macroinvertebrate assemblages is 
widely recognised in the literature (Pardo \& Armitage, 1997; Robson \& Chester, 1999; Buss et al., 2004; Costa \& Melo, 2008) and results from the differential availability of feeding resources and refuges against predation or flow disturbance (Pardo \& Armitage, 1997; Buss et al., 2004). For instance, litter patches are relatively unstable and provide contrasting food resources for their fauna compared to rocky (gravel + stones) substrata. In fact, we observed larger differences in faunal composition between litter and rocky substrata than between gravel and stones.

The importance of the beta diversity component at the finest spatial scale $\left(\beta_{1}\right)$ was dependent on substratum type. There was low beta diversity of the macroinvertebrate fauna among litter patches within riffles (prop $p_{\exp }>\mathrm{obs}>0.999$ ), intermediate among stones ( prop $_{\exp }>\mathrm{obs}=0.879$ ) and high among gravel

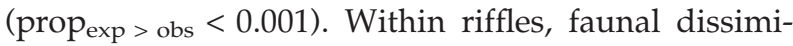
larities among litter packs were lower than expected. In contrast, there was high dissimilarity among patches of gravel in the same riffle. Our results thus indicated that, within riffles, the fauna in gravel is patchier than that in litter packs.

Robson et al. (2005) employed nested ANOva to partition the variation in species richness and abundance among five spatial scales (stones, group of stones, riffles, reaches and stream segment). They found that most of the variation was accounted for by the lowest level (stones) and that such a pattern agreed with previous works on stony streams employing nested ANOVA. Despite of the lack of a study comparing the relationship among diversity components using nested ANOVA and additive partitioning, it seems that the variation among stones in the study of Robson et al. (2005) is equivalent to our $\beta_{1}$ component. Assuming this equivalence, it is interesting to note that (independent of its significance in relation to a null model) the magnitude of the $\beta_{1}$ (among Surber units) component was slightly lower than those observed among riffles $\left(\beta_{2}\right)$ and reaches $\left(\beta_{3}\right)$. This contrasts with the results of Robson et al. (2005) (and studies summarised in their Table 1) in which variation among riffles or stream reaches was much smaller than that among stones or sampling units. It would be useful to know if such differences between systems are real or simply a consequence of differing analytical techniques (Nested ANOVA and Additive partitioning).
The relatively high similarity in faunal composition observed among riffles and stream reaches within each stream segment agrees with some previous studies (Robson \& Chester, 1999; Parsons et al., 2003; Ciesielka \& Bailey, 2007). The high similarity at these two levels of the spatial hierarchy may in part be caused by the drift of individuals (Ramírez \& Pringle, 2001; Callisto \& Goulart, 2005). This homogenising influence of drift is particularly likely given the short distances between riffles $(50 \mathrm{~m})$ and between stream reaches $(800 \mathrm{~m})$. However, some previous studies have reported large differences among riffles and among stream reaches within stream segments (Downes et al., 2000; Heino et al., 2004, 2005). Such contradictory results could partially be explained by the spatial extent of riffles or reaches in the studies cited. For instance, studies dealing with short distances $(<3 \mathrm{~km})$ usually find high similarities among riffles or reaches (Robson \& Chester, 1999; Parsons et al., 2003; Ciesielka \& Bailey, 2007), whereas studies dealing with greater distances find the opposite (Downes et al., 2000; Heino et al., 2004, 2005). An additional possibility contributing to low dissimilarity among patches at these two scales is the preponderance of different habitats between riffles or reaches, such as long pools. Despite adult dispersal, long pools may constitute barriers to drifting organisms, not only due to reduced flow but also to fish predation (Allan \& Castillo, 2007).

We found important differences in family composition among the three streams studied, revealed both in the UPGMA classification (Fig. 3) and in the diversity partitioning analyses (high $\beta_{4}$ component; Fig. 4). This agrees with previous studies addressing this spatial scale (Heino et al., 2004, 2005; Robson et al., 2005; Ciesielka \& Bailey, 2007; Clarke et al., 2008). Heino, Muotka \& Paavola (2003) suggested that differences in faunal composition among streams, even those in the same catchment, may be caused by differences in environmental conditions. In this study, however, we deliberately opted to study headwater streams that were located in the same catchment and were similar in size and physical and chemical characteristics. Accordingly, it is unlikely that the observed differences in family composition among streams resulted from differences in environmental conditions. An alternative mechanism generating differences among streams is restriction in the dispersal of adults. 
Finn \& Poff (2005) studied streams similar to each other in the Rocky Mountains (U.S.A.) and concluded that the terrestrial matrix could restrict the dispersal of adults, even to adjacent areas. This could lead to the partial isolation of headwater streams and result in differentiated faunas (Hynes, 1975; Poole, 2002). However, such a restriction in dispersal may not occur for many species (e.g.Masters et al., 2007) rendering a simple interpretation of our results difficult. This study was restricted to families and one may argue that this dispersalrestriction may not apply because many families might contain at least some species with high dispersal capabilities and, thus, would be distributed homogeneously in the region. However, a significant proportion of macroinvertebrate families in the Neotropical region are represented by a single species in a catchment. For instance, Melo \& Froehlich (2001) present a list of 162 macroinvertebrate morphospecies present in 10 streams in the same catchment and found that out the 45 families, 20 occurred with a single species and nine with two or three species.

The high beta component observed at our coarsest (stream) scale not only agrees with the several previous studies cited above, but could be expected from the ubiquitous distance-decay in similarity observed for a range of organisms, scales and ecosystems (Nekola \& White, 1999). However, this could be regarded as at odds with observations of Mac Nally et al. (2004) in a study of the species composition of birds and butterflies in a nested hierarchy of sites, canyons and mountain ranges. They found that similarity increased with spatial grain (e.g. the similarity among canyons was greater than among sites in the same canyon) and that this resulted from the presence at the upper scale of most of the habitat patches observed at the lower scale. In contrast to the study of Mac Nally et al. (2004), however, our intermediate spatial scales (riffles, reaches) probably did not add much environmental heterogeneity and, thus, our result substantially agree with the distance-decay model of similarity.

For the three substratum types studied, the alpha diversity at the finest scale was lower than expected. This has also been observed in previous studies employing additive partitioning, including beetles associated with trees [separated into common and rare species (Gering et al., 2003) or not separated (Crist et al., 2003)] and trees and woody understorey plants (Chandy et al., 2006). This pattern probably reflects the aggregation of individuals at fine scales which, in turn, could result both from restrictions in dispersal (Bunn \& Hughes, 1997; Finn \& Poff, 2005), differences in microhabitat and resource availability (Egglishaw, 1964) or competitive interactions (McAuliffe, 1984). Future studies could investigate the aggregation pattern in relation to continuous measures of spatial distance (rather than discontinuous scales such as plots or stream reaches) and assess determinants of community structure in major segments of this continuous hierarchy.

As in previous studies addressing several spatial scales, this study included little replication at the coarsest scale (stream segment) and was conducted during a single season (dry period) (Downes et al., 2000; Heino et al., 2004; Robson \& Clay, 2005; Robson et al., 2005). The effect of season may be of particular importance and a different pattern may occur in the rainy season. For instance, increased flow may cause drift of organisms that would homogenise their distribution on the stream bed (Townsend \& Hildrew, 1976). However, a few studies have indicated that the effect of spates may be heterogeneous and dependent on substratum type (e.g. loose or fixed stones; Matthaei et al., 2000) and specific places in the streambed (Melo et al., 2003). Accordingly, the relative importance of each beta component may depend on season and, thus, care should be taken in the extrapolation of our results.

Despite these limitations, this study presented effective evidence for the value of diversity partitioning as a tool for identifying the primary sources of diversity in streams (Ribeiro et al., 2008). We found that variation among stream riffles and reaches was low. For instance, sampling in only a single riffle in a single reach would be enough to collect $75 \%$ of the taxa using $17 \%$ of the sample effort. This finding indicates that intensive sampling (many riffles and reaches) at a few stream sites does not result in the efficient assessment of diversity in a region. This is particularly relevant for biomonitoring programmes, particularly when human and economic resources are scarce (Lenat \& Resh, 2001). Therefore, expenditure of resources in diversity studies and biomonitoring programme can be made more effective by prioritising (i) large spatial coverage (many stream sites) and (ii) substratum diversity. 


\section{Acknowledgments}

We are grateful to our colleagues of the Laboratório de Ecologia de Bentos ICB/UFMG, especially to Clarissa Dantas, for extensive help during fieldwork and sorting of samples in the laboratory. Diego Macedo helped in the confection of the map. Comments from Manuel Graça helped to improve the first version of this manuscript. Alan Hildrew, Belinda Robson and one anonymous referee provided extensive comments that improved the final version of the manuscript. ASM received a research grant and a research fellowship from the Conselho Nacional de Desenvolvimento Científico e Tecnológico (CNPq no. 476304/2007-5; 302482/2008-3) and the International Foundation for Science (IFS no. A/4107-1). This research was partially supported by CNPq (Grants No. 475622/2006-5) and FAPEMIG (Grants No. CRA 626/06).

\section{References}

Allan J.D. \& Castillo M.M. (2007) Stream Ecology: Structure and Function of Running Waters. Springer, New York.

Bispo P.C., Oliveira L.G., Crisci V.L. \& Silva M.M. (2001) A pluviosidade como fator de alteração da entomofauna bentônica (Ephemeroptera, Plecoptera e Trichoptera) em córregos do Planalto Central do Brasil. Acta Limnologica Brasiliensia, 13, 1-9.

Bonada N., Rieradevall M., Dallas H., Davis J., Day J., Figueroa R., Resh V.H. \& Prat N. (2008) Multi-scale assessment of macroinvertebrate richness and composition in Mediterranean-climate rivers. Freshwater Biology, 53, 772-788.

Bouckaert F.W. \& Davis J. (1998) Microflow regimes and the distribution of macroinvertebrates around stream boulders. Freshwater Biology, 40, 77-86.

Boyero L. \& Bailey R.C. (2001) Organization of macroinvertebrate communities at a hierarchy of spatial scales in a tropical stream. Hydrobiologia, 464, 219-225.

Bunn S.E. \& Hughes J.M. (1997) Dispersal and recruitment in streams: evidence from genetic studies. Journal of the North American Benthological Society, 16, 338-346.

Buss D.F., Baptista D.F., Nessimian J.L. \& Egler M. (2004) Substrate specificity, environmental degradation and disturbance structuring macroinvertebrate assemblages in Neotropical streams. Hydrobiologia, 518, 179-188.

Callisto M. \& Goulart M. (2005) Invertebrate drift along a longitudinal gradient in a Neotropical stream in Serra do Cipó National Park, Brazil. Hydrobiologia, 539, 4756.

(c) 2009 Blackwell Publishing Ltd, Freshwater Biology, 55, 424-435
Callisto M., Moreno P. \& Barbosa F.A.R. (2001) Habitat diversity and benthic functional trophic groups at Serra do Cipó, Southeast Brazil. Revista Brasileira de Biologia, 61, 259-266.

Chandy S., Gibson D.J. \& Robertson P.A. (2006) Additive partitioning of diversity across hierarchical spatial scales in a forested landscape. Journal of Applied Ecology, 43, 792-801.

Ciesielka I.K. \& Bailey R.C. (2007) Hierarchical structure of stream ecosystems: consequences for bioassessment. Hydrobiologia, 586, 57-67.

Clarke A., Mac Nally R., Bond N. \& Lake P.S. (2008) Macroinvertebrate diversity in headwater streams: a review. Freshwater Biology, 53, 1707-1721.

Costa S.S. \& Melo A.S. (2008) Beta diversity in stream macroinvertebrate assemblages: among-site and among-microhabitat components. Hydrobiologia, 598, 131-138.

Crist T.O., Veech J.A., Gering J.C. \& Summerville K.S. (2003) Partitioning species diversity across landscapes and regions: a hierarchical analysis of $\alpha, \beta$, and $\gamma$ diversity. The American Naturalist, 162, 734-743.

Downes B.J., Lake P.S. \& Schreiber E.S.G. (1993) Spatial variation in the distribution of stream invertebrates: implications of patchiness for models of community organization. Freshwater Biology, 30, 119-132.

Downes B.J., Hindell J.S. \& Bond N.R. (2000) What's in a site? Variation in lotic macroinvertebrate density and diversity in a spatially replicated experiment. Austral Ecology, 25, 128-139.

Dudgeon D., Arthington A.H., Gessner M.O. et al. (2006) Freshwater biodiversity: importance, threats, status and conservation challenges. Biological Review, 81, 163182.

Egglishaw H.J. (1964) The distributional relationship between the bottom fauna and plant detritus in streams. Journal of Animal Ecology, 33, 463-476.

Erös T. (2007) Partitioning the diversity of riverine fish: the roles of habitat types and non-native species. Freshwater Biology, 52, 1400-1415.

Finn D.S. \& Poff N.L. (2005) Variability and convergence in benthic communities along the longitudinal gradients of four physically similar Rocky Mountain streams. Freshwater Biology, 50, 243-261.

Frissell C.A., Liss W.J., Warren C.E. \& Hurley M.D. (1986) A hierarchical framework for stream habitat classification - viewing streams in a watershed context. Environmental Management, 10, 199-214.

Gering J.C., Crist T.O. \& Veech J.A. (2003) Additive partitioning of species diversity across multiple spatial scales: implications for regional conservation of biodiversity. Conservation Biology, 17, 488-499. 
434 R. Ligeiro et al.

Giller P.S., Hildrew A.G. \& Raffaelli D.G. (Eds) (1994) Aquatic Ecology: Scale, Pattern and Process. Blackwell Science, Oxford.

Heino J., Muotka T. \& Paavola R. (2003) Determinants of macroinvertebrate diversity in headwater streams: regional and local influences. Journal of Animal Ecology, 72, 425-434.

Heino J., Louhi P. \& Muotka T. (2004) Identifying the scales of variability in stream macroinvertebrate abundance, functional composition and assemblage structure. Freshwater Biology, 49, 1230-1239.

Heino J., Parviainen J., Paavola R., Jehle M., Louhi P. \& Muotka T. (2005) Characterizing macroinvertebrate assemblage structure in relation to stream size and tributary position. Hydrobiologia, 539, 121-130.

Hildrew A.G. \& Giller P.S. (1994) Patchiness, species interactions and disturbance in the stream benthos. In: 'Aquatic Ecology: Scale, Pattern and Process (Eds P.S. Giller, A.G. Hildrew \& D.G. Raffaelli), pp. 21-62. Blackwell Science, Oxford.

Holzenthal R.W. (1997) The caddisfly (Trichoptera) family Atriplectididae in the Neotropics. In: Proceedings of the 8th International Symposium on Trichoptera (Eds R.W. Holzenthal \& O.S. Flint Jr), pp. 157-165. Ohio Biological Survey, Columbus, $\mathrm{OH}$.

Huamantinco A.A. \& Nessimian J.L. (2003) A new species of Antactoercia Ulmer, 1907 (Trichoptera: Limnephilidae) from Southeastern Brazil. Aquatic Insects, 25, 225-231.

Hynes H.B.N. (1975) The stream and its valley. Verhandlungen der Internationalen Vereinigung für Theoretische und Angewandte Limnologie, 19, 1-15.

Lenat D.R. \& Resh V.H. (2001) Taxonomy and stream ecology - the benefits of genus- and species-level identifications. Journal of the North American Benthological Society, 20, 287-298.

Li J., Herlihy A., Gerth W., Kaufmann P., Gregory S., Urquhart S. \& Larsen D.P. (2001) Variability in stream macroinvertebrates at multiple spatial scales. Freshwater Biology, 46, 87-97.

Mac Nally R., Fleishman E., Bulluck L.P. \& Betrus C.J. (2004) Comparative influence of spatial scale on beta diversity within regional assemblages of birds and butterflies. Journal of Biogeography, 31, 917-929.

Malmqvist B. (2002) Aquatic invertebrates in riverine landscapes. Freshwater Biology, 47, 679-694.

Marchant R. (1990) Robustness of classification and ordination techniques applied to macroinvertebrate communities from the La Trobe River, Victoria. Australian Journal of Marine and Freshwater Research, 41, 493-504.

Masters Z., Peteresen I., Hildrew A.G. \& Ormerod S.J. (2007) Insect dispersal does not limit the biological recovery of streams from acidification. Aquatic Conservation: Marine and Freshwater Ecosystems, 17, 375383.

Matthaei C.D., Arbuckle C.J. \& Townsend C.R. (2000) Stable surface stones as refugia for invertebrates during disturbance in a New Zealand stream. Journal of the North American Benthological Society, 19, 82-93.

McAuliffe J.R. (1984) Competition for space, disturbance, and the structure of a benthic stream community. Ecology, 65, 894-908.

Melo A.S. (2005) Effects of taxonomic and numeric resolution on the ability to detect ecological patterns at a local scale using stream macroinvertebrates. Archiv für Hydrobiologie, 164, 309-323.

Melo A.S. \& Froehlich C.G. (2001) Macroinvertebrates in neotropical streams: richness patterns along a catchment and assemblage structure between 2 seasons. Journal of the North American Benthological Society, 20, 116.

Melo A.S., Niyogi D.K., Matthaei C.D. \& Townsend C.R. (2003) Resistance, resilience, and patchiness of invertebrate assemblages in native tussock and pasture streams in New Zealand after a hydrological disturbance. Canadian Journal of Fisheries and Aquatic Sciences, 60, 731-739.

Myers N., Mittermeier R.A., Mittermeier C.G., Fonseca G.A.B. \& Kent J. (2000) Biodiversity hotspots for conservation priorities. Nature, 403, 853-858.

Mykrä H., Heino J. \& Muotka T. (2007) Scale-related patterns in the spatial and environmental components of stream macroinvertebrate assemblage variation. Global Ecology and Biogeography, 16, 149-159.

Nekola F.C. \& White P.S. (1999) The distance decay of similarity in biogeography and ecology. Journal of Biogeography, 26, 867-878.

Norris R.H. (1995) Biological monitoring: the dilemma of data analysis. Journal of the North American Benthological Society, 14, 440-450.

Økland R.H., Eilertsen O. \& Økland T. (1990) On the relationship between sample plot size and beta diversity in boreal coniferous forests. Vegetatio, 87, 187-192.

Pardo I. \& Armitage P.D. (1997) Species assemblages as descriptors of mesohabitats. Hydrobiologia, 344, 111128.

Parsons M., Thoms M.C. \& Norris R.H. (2003) Scales of macroinvertebrate distribution in relation to the hierarchical organization of river systems. Journal of the North American Benthological Society, 22, 105-122.

Poff N.L. (1997) Landscapes filters and species traits: towards mechanistic understanding and prediction in stream ecology. Journal of the North American Benthological Society, 16, 391-409. 
Poole G.C. (2002) Fluvial landscape ecology: addressing uniqueness within the river discontinuum. Freshwater Biology, 47, 641-660.

Ramírez A. \& Pringle C.M. (2001) Spatial and temporal patterns of invertebrate drift in streams draining a Neotropical landscape. Freshwater Biology, 46, 47-62.

Ribeiro D.B., Prado P.I., Brown .K.S. Jr \& Freitas A.V.L. (2008) Additive partitioning of butterfly diversity in a fragmented landscape: importance of scale and implications for conservation. Diversity and Distributions, 14, 961-968.

Robson B.J. \& Chester E.T. (1999) Spatial patterns of invertebrate species richness in a river: the relationship between riffles and microhabitats. Australian Journal of Ecology, 24, 599-607.

Robson B.J. \& Clay C.J. (2005) Local and regional macroinvertebrate diversity in the wetlands of a cleared agricultural landscape in south-western Victoria, Australia. Aquatic Conservation: Marine and Freshwater Ecosystems, 15, 403-414.

Robson B.J., Hogan M. \& Forrester T. (2005) Hierarchical patterns of invertebrate assemblage structure in stony upland streams change with time and flow permanence. Freshwater Biology, 50, 944-953.

Schmera D. \& Erös T. (2008) Linking scale and diversity partitioning in comparing species diversity of caddisflies in riffle and pool habitats. Fundamental and Applied Limnology, 172, 205-215.

Stendera S.E.S. \& Johnson R.K. (2005) Additive partitioning of aquatic invertebrate species diversity across multiple spatial scales. Freshwater Biology, 50, 13601375.

Tockner K., Ward J.V., Edwards P.J. \& Kollmann J. (2002) Riverine landscapes: an introduction. Freshwater Biology, 47, 497-500.
Townsend C.R. (1989) The patch dynamics concept of stream community ecology. Journal of the North American Benthological Society, 8, 36-50.

Townsend C.R. \& Hildrew A.G. (1976) Field experiments on the drifting, colonization and continuous redistribution of stream benthos. Journal of Animal Ecology, 45, 759-772.

Townsend C.R., Arbuckle C.J., Crowl T.A. \& Scarsbrook M.R. (1997) The relationship between land use and physicochemistry, food resources and macroinvertebrate communities in tributaries of the Taieri River, New Zealand: a hierarchically scaled approach. Freshwater Biology, 37, 177-191.

Tylianakis J.M., Klein A.M., Lozada T. \& Tscharntke T. (2006) Spatial scale of observation affects $a, b$ and $g$ diversity of cavity-nesting bees and wasps across a tropical land-use gradient. Journal of Biogeography, 33, 1295-1304.

Veech J.A. \& Crist T.O. (2007) PARTITION: Software for Hierarchical Additive Partitioning of Species Diversity. Version 2.0. Available at: http://www.users.muohio. edu/cristto/partition.htm (last accessed on 28 July 2009).

Wagner H.H., Wildi O. \& Ewald C.W. (2000) Additive partitioning of plant species diversity in an agricultural mosaic landscape. Landscape Ecology, 15, 219227.

Ward J.V., Tockner K., Arscott D.B. \& Claret C. (2002) Riverine landscape diversity. Freshwater Biology, 47, 517-539.

Wu J. \& Loucks O.L. (1995) From balance of nature to hierarchical patch dynamics: a paradigm shift in ecology. The Quarterly Review of Biology, 70, 439-466.

(Manuscript accepted 3 July 2009) 